\title{
A Novel Purification Method for CNS Projection Neurons Leads to the Identification of Brain Vascular Cells as a Source of Trophic Support for Corticospinal Motor Neurons
}

\author{
Jason C. Dugas, ${ }^{\star}$ Wim Mandemakers, ${ }^{\star}$ Madolyn Rogers, Adiljan Ibrahim, Richard Daneman, and Ben A. Barres \\ Department of Neurobiology, Stanford University School of Medicine, Stanford, California 94305-5125
}

\begin{abstract}
One of the difficulties in studying cellular interactions in the CNS is the lack of effective methods to purify specific neuronal populations of interest. We report the development of a novel purification scheme, cholera toxin $\beta$ (CTB) immunopanning, in which a particular CNS neuron population is selectively labeled via retrograde axonal transport of the cell-surface epitope CTB, and then purified via immobilization with anti-CTB antibody. We have demonstrated the usefulness and versatility of this method by purifying both retinal ganglion cells and corticospinal motor neurons (CSMNs). Genomic expression analyses of purified CSMNs revealed that they express significant levels of many receptors for growth factors produced by brain endothelial cells; three of these factors, CXCL12, pleiotrophin, and IGF2 significantly enhanced purified CSMN survival, similar to previously characterized CSMN trophic factors BDNF and IGF1. In addition, endothelial cell conditioned medium significantly promoted CSMN neurite outgrowth. These findings demonstrate a useful method for the purification of several different types of CNS projection neurons, which in principle should work in many mammalian species, and provide evidence that endothelial-derived factors may represent an overlooked source of trophic support for neurons in the brain.
\end{abstract}

Key words: corticospinal motoneurons; immunopanning; endothelial cells; IGF2; CXCL12; SDF1; pleiotrophin

\section{Introduction}

A paramount question in neuroscience is to understand the cellcell interactions that control neuronal survival, development, and function. Progress in this field of research, however, has been limited by the inability to separate most individual neuronal populations from neighboring neuronal and glial cell types. Although several groups have succeeded in purifying neuronal populations via immunopanning or fluorescence-activated cell sorting (FACS), these procedures have some significant drawbacks. Immunopanning is relatively inexpensive, gentle on cells, and can produce very good yields (Barres et al., 1988). However, immunopanning is limited by the requisite availability of an antibody that recognizes a cell surface epitope present exclusively on the cell population of interest, and few if any monoclonal antibodies have been developed that are neuron type specific. FACS is a more versatile technique, because specific populations can be labeled by genetically encoded or retrogradely transmitted fluo-

\footnotetext{
Received May 1, 2008; revised June 23, 2008; accepted June 30, 2008.

This work was supported by National Eye Institute Regeneration Grant R01 EY011310 and the Adelson Medical Research Foundation. W.M. was supported by National Multiple Sclerosis Society Postdoctoral Fellowship FG 1434A-1 and Netherlands Organization for Scientific Research TALENT Stipend S 93-380. M.R. was supported by a Howard Hughes Medical Institute Predoctoral Fellowship. We thank Dr. Sue McConnell for the generous gift of a CTIP2 antibody. Detailed protocols are available on request from B. A. Barres at barres@stanford.edu.

*J.C.D. and W.M. contributed equally to this work.

Correspondence should be addressed to Dr. Jason C. Dugas, Department of Neurobiology, Stanford University School of Medicine, Fairchild Building, Room D205, 299 Campus Drive, Stanford, CA 94305-5125. E-mail: jcdugas@alum.mit.edu.

W. Mandemakers' present address: Department of Human Genetics, Katholieke Universiteit Leuven and Vlaams Instituut voor Biotechnologie, Herestraat 49 bus 602, Leuven 3000, Belgium.

DOI:10.1523/JNEUROSCI.2010-08.2008

Copyright (C) 2008 Society for Neuroscience $\quad 0270-6474 / 08 / 288294-12 \$ 15.00 / 0$
}

rescent tracers, but FACS requires the availability of expensive machinery and often adversely affects the viability of fragile cells such as neurons. Here, we describe a novel purification method that combines the versatility of retrograde labeling with the advantages of immunopanning. We inject targeted axonal tracts with cholera toxin $\beta$ (CTB) adsorbed to fluorescent beads to retrogradely label a neuronal population of interest. The tissue containing the labeled neuron cell bodies is then dissected and dissociated, and the neurons of interest are specifically purified via immunopanning with an anti-CTB antibody.

Our method can be used to highly purify any neuronal cell type whose projections can be selectively retrogradely labeled. We have demonstrated the efficacy of this method by purifying to $>99 \%$ purity two populations of CNS neurons, retinal ganglion cells (RGCs), and corticospinal motoneurons (CSMNs) from early postnatal rat pups. CSMNs residing in cortical layer $\mathrm{V}$ of the brain project their axons to the spinal cord where they connect with spinal motor neurons (SMNs) located in the ventral horn of the spinal cord. CSMNs are in charge of controlling voluntary movements, and their importance becomes obvious in situations where this network breaks down. For instance, both CSMNs and SMNs progressively degenerate in amyotrophic lateral sclerosis (ALS) (Pasinelli and Brown, 2006). In addition, damage to CSMN axons and their subsequent failure to regenerate underlie the loss of motor function in severe spinal cord injuries (Schwab, 2002).

Recently, there has been great progress on the anatomical, morphological and genetic characterization of developing CSMNs. However, most previous studies examining the growth and 
survival requirements of CSMNs have been performed using in vivo axotomy studies, in which it is difficult to separate direct versus indirect effects on the CSMNs (Giehl et al., 1998; Hammond et al., 1999; Schütte et al., 2000; Giehl et al., 2001; Lu et al., 2001; Tuszynski et al., 2003). More recently, two groups have succeeded in purifying CSMNs via FACS (Junger and Junger, 1998; Arlotta et al., 2005; Ozdinler and Macklis, 2006) and have generated the first direct data on CSMN survival requirements. Our method produces significantly higher yields than FACS purification, and agrees with many previous studies in finding that brain derived neurotrophic factor (BDNF) and insulin-like growth factor 1 (IGF1) are important survival factors for early postnatal CSMNs (Giehl et al., 1998, 2001; Hammond et al., 1999; Schütte et al., 2000; Lu et al., 2001; Ozdinler and Macklis, 2006). We also analyzed purified CSMN gene expression by gene chip hybridization, which has revealed that CSMNs express numerous receptors for growth factors secreted by vascular cells in the brain (endothelial cells and pericytes). After testing these growth factors, we discovered that insulin-like growth factor 2 (IGF2), chemokine (C-X-C motif) ligand 12 (CXCL12, also known as $\mathrm{SDF} 1 \alpha$ ), and pleiotrophin (PTN), which are all highly expressed by vascular cells in the developing brain, are equally as potent as BDNF or IGF1 at supporting CSMN survival. In addition, we found that endothelial cell conditioned medium (ECM) significantly promotes CSMN neurite outgrowth. These data suggest a hitherto unsuspected role of brain vascular cells in supporting CNS neuron survival.

\section{Materials and Methods}

Adsorption of cholera toxin $\beta$ to Lumafluor Retrobeads IX. Green Lumafluor Retrobeads IX $(20 \mu \mathrm{l})$ were combined with CTB $(100 \mu \mathrm{l}$ of 1 $\mathrm{mg} / \mathrm{ml}$ solution; List Biological Laboratories). The solution was protected from light and incubated overnight at $4^{\circ} \mathrm{C}$ while gently shaking to facilitate adsorption of CTB to the beads. Microspheres were pelleted by ultracentrifugation at $4^{\circ} \mathrm{C}$ for $45 \mathrm{~min}$ at $60,000 \mathrm{rpm}$ in a benchtop ultracentrifuge (Beckman optima TLX; TLA 120.2 rotor). Subsequently, 100 $\mu l$ of the supernatant was removed and the pellet was resuspended in the remaining $20 \mu \mathrm{l}$, then stored at $4^{\circ} \mathrm{C}$ until use.

Retrograde labeling of RGCs. Early postnatal [postnatal day 2 (P2)-P6] Sprague Dawley rats (Charles River) were anesthetized using isoflurane. The skull was exposed on the dorsal surface by making a small longitudinal incision in the skin midline. Injections were performed without the aid of a stereotactic device; in early postnatal rats, the needle could be accurately positioned $2 \mathrm{~mm}$ lateral to the sagittal sinus just anterior to its intersection with the transverse sinus, at a depth of $4 \mathrm{~mm}$. At these coordinates, the injection site was at the intersection of the dorsal midbrain and diencephalon (Potts et al., 1982). The skull was gently punctured with a 30-gauge needle, allowing easy penetration of the injection needle to the required depth, after which $1 \mu \mathrm{l}$ of CTB-adsorbed green Lumafluor Retrobeads IX was injected into the superior collicular brachium bilaterally. Injections were performed over a time span of $\sim 1 \mathrm{~min}$ with a $5 \mu$ l Hamilton syringe. After the injection, the wound was closed with surgical glue. After recovery, the animals were returned to their mother for 2-3 d to allow complete retrograde transport of the injected tracer.

Retrograde labeling of CSMNs. Age P1-P8 Sprague Dawley rats were anesthetized using isoflurane. An incision was made in the skin at the back of the skull, and muscle tissue and the atlanto-occipital membrane were reflected, exposing the underlying dura. Next, the injection needle was lowered in between the foramen magnum and the atlas into the pyramidal decussation at the junction of the medulla and cervical spinal cord. Subsequently, $1 \mu \mathrm{l}$ of CTB-adsorbed green Lumafluor Retrobeads IX was injected over a time span of $\sim 1$ min with a $5 \mu$ l Hamilton syringe using a 32-gauge needle. After the injection, the needle was slowly retracted, muscle tissue was sutured, and the skin was closed using surgical glue. After recovery, the animals were returned to their mother for 2-3 d to allow complete retrograde transport of the injected tracer.

RGC purification and culture. RGCs from P2-P6 Sprague Dawley rats that had been labeled via retrograde tracing with CTB-adsorbed Retrobeads were purified as described previously with some modifications (Barres et al., 1988). Briefly, dissected retinas were analyzed under a fluorescent inverted microscope, and labeled retinas were selected for CTB panning. Unlabeled retinas were used in parallel for established immunopanning using the Thy1.1 cell surface epitope expressed by RGCs. Retinas were enzymatically dissociated in papain (Worthington) at $37^{\circ} \mathrm{C}$ for $30 \mathrm{~min}$ then gently triturated to create a single-cell suspension. The cell suspension was first incubated sequentially on two Griffonia (Bandeiraea) simplicifolia lectin I (BSLI; Vector Laboratories)-coated Petri dishes for $30 \mathrm{~min}$ each to remove most microglia and macrophages from the cell suspension. Subsequently, in the case of CTB immunopanning, the cells were incubated in a closed tube at $37^{\circ} \mathrm{C}$ for $1 \mathrm{~h}$ to allow recovery of the CTB epitope to the cell surface, after which the cells were poured onto a plate coated first with anti-mouse IgG Fc $\gamma$ fragmentspecific antibody (Jackson ImmunoResearch) overnight, then coated with $140 \mu \mathrm{g}$ mouse monoclonal anti-CTB (mouse monoclonal IgG1, clone 3D11; Biodesign International) and allowed to bind for $1 \mathrm{~h}$ at room temperature. In the case of Thyl immunopanning, the cell suspension was incubated on a T11D7 (monoclonal supernatant IgM antibody against mouse Thy1.1; American Type Culture Collection)-coated dish under the same conditions. After extensive rinsing, cells that remained attached to the plate were released using trypsin (Sigma-Aldrich) and plated on glass coverslips (Carolina Science and Math) coated with polyD-lysine (pDL; $70 \mathrm{kDa}$; Sigma) and Cultrex mouse laminin (Trevigen) in serum-free media as described previously (Meyer-Franke et al., 1995). For in vitro synaptogenesis assays, previously published protocols were followed (Ullian et al., 2001; Christopherson et al., 2005).

CSMN purification and culture. After retrograde labeling of CSMNs with CTB, animals were killed and the cortices were isolated by removal of the midbrain, hippocampi, olfactory bulbs, and meninges. Cortices were examined under an inverted fluorescence microscope and only labeled cortices were used (see Fig. 2 B). Cortices were enzymatically dissociated with papain $(800 \mathrm{U})$ and L-cysteine $(3.2 \mathrm{mg}$, for papain activation; Sigma) for $1 \mathrm{~h}$ at $34^{\circ} \mathrm{C}$ in a sucrose buffer containing $152 \mathrm{~mm}$ sucrose, $26 \mathrm{~mm} \mathrm{NaHCO}, 0.9 \mathrm{~mm} \mathrm{NaH} \mathrm{PO}_{4}, 1.8 \mathrm{~mm} \mathrm{CaCl}_{2}, 0.8 \mathrm{~mm}$ $\mathrm{MgCl}_{2}, 5.4 \mathrm{~mm} \mathrm{KCl}, 25 \mathrm{~mm}$ glucose, $5 \mu \mathrm{g} / \mathrm{ml}$ phenol red, $50 \mu \mathrm{M} \mathrm{APV}, 800$ $\mu \mathrm{M}$ kynurenic acid, $1 \mu \mathrm{g} / \mathrm{ml}$ glutathione (reduced), $2.5 \mu \mathrm{g} / \mathrm{ml}$ catalase, $2.5 \mu \mathrm{g} / \mathrm{ml}$ superoxide dismutase, $1 \mu \mathrm{g} / \mathrm{ml} \mathrm{DL}-\alpha$-tocopherol, $1 \mu \mathrm{g} / \mathrm{ml} \mathrm{DL}$ $\alpha$-tocopherol acetate (all from Sigma), HEPES (10 mm; USB), sodium pyruvate ( $0.23 \mathrm{~mm}$; Invitrogen), and DNase I (5000 units; Worthington). Sucrose buffer was equilibrated in $10 \% \mathrm{CO}_{2}$ before use, and during digestion was maintained under a stream of $95 \% \mathrm{O}_{2} / 5 \% \mathrm{CO}_{2}$. Cortices were then mechanically dissociated first with a $25 \mathrm{ml}$ pipette, then with a fire-polished glass pipette in the sucrose buffer plus $1.5 \mathrm{mg} / \mathrm{ml}$ ovomucoid trypsin inhibitor (Roche) to inhibit the papain. Dissociated cells were spun through sucrose buffer with $5 \mathrm{mg} / \mathrm{ml}$ ovomucoid trypsin inhibitor for $15 \mathrm{~min}$ at 220 relative centrifugal force ( $\mathrm{rff}$ ), resuspended in sucrose buffer, and spun through a cushion of $4 \%$ BSA (Sigma) for 10 $\mathrm{min}$ at $220 \mathrm{rcf}$. Cells were resuspended in sucrose buffer and allowed to recover for $1 \mathrm{~h}$ at $37^{\circ} \mathrm{C}$ in a $10 \% \mathrm{CO}_{2}$ incubator. During recovery, cells were gradually switched to a nonsucrose buffer in a stepwise manner by adding saline buffer every $10 \mathrm{~min}$. Saline buffer was as described above, but lacking sucrose, $\mathrm{NaHCO}_{3}$, and DNase I, and containing $102 \mathrm{~mm}$ $\mathrm{NaCl}$ (Fisher Scientific). Cells were then passed through a Nitex filter (20 $\mu \mathrm{m}$ pore size; Sefar America) and poured sequentially onto two Petri dishes coated with $2.5 \mu \mathrm{g} / \mathrm{ml}$ BSLI (Vector Laboratories). Cells were incubated for $20 \mathrm{~min}$ on each dish in $5 \% \mathrm{CO}_{2}$ at room temperature. Microglia, endothelial cells, and red blood cells adhered to the BSLI plates. The supernatant was then poured onto an anti-CTB-coated dish (140 $\mu \mathrm{g}$ for P3, $210 \mu \mathrm{g}$ for P7). This dish was incubated for $45 \mathrm{~min}$ at room temperature in $5 \% \mathrm{CO}_{2}$. After extensive rinsing, adhered cells were removed by incubation in $0.25 \%$ trypsin (Sigma) for $6 \mathrm{~min}$ at $37^{\circ} \mathrm{C}$. Trypsin was inhibited by addition of $30 \%$ heat-inactivated fetal calf serum (Invitrogen), and cells were mechanically dislodged by pipetting and pelleted at $220 \mathrm{rcf}$ for $10 \mathrm{~min}$. Cells were resuspended in growth medium 
and plated at a density of 35 cells $/ \mathrm{mm}^{2}$ onto either 96-well tissue-culture plates or onto $12 \mathrm{~mm}$ glass coverslips in 24-well plates. In either case, the substrate was coated with $10 \mu \mathrm{g} / \mathrm{ml} \mathrm{pDL}$ and $2 \mu \mathrm{g} / \mathrm{ml}$ Cultrex mouse laminin I overnight. Plates were spun down at $150 \mathrm{rcf}$ for $2 \mathrm{~min}$ to facilitate adhesion of the CSMNs to the substrate.

CSMNs were cultured in growth medium consisting of 50\% DMEM and $50 \%$ Neurobasal containing $1 \mathrm{~mm}$ sodium pyruvate, $2 \mathrm{~mm}$ L-glutamine, $100 \mathrm{U}$ penicillin, $100 \mu \mathrm{g} / \mathrm{ml}$ streptomycin (all from Invitrogen), $100 \mu \mathrm{g} / \mathrm{ml}$ human transferrin, $60 \mathrm{ng} / \mathrm{ml}$ progesterone, $16 \mu \mathrm{g} / \mathrm{ml}$ putrescine, $40 \mathrm{ng} / \mathrm{ml}$ sodium selenite, $40 \mathrm{ng} / \mathrm{ml}$ thyroxine, $30 \mathrm{ng} / \mathrm{ml}$ triidothyronine, $35 \mathrm{~mm}$ glucose, $0.34 \%$ BSA (all from Sigma), and B27 supplement (Invitrogen) or SCAVEGR antioxidants (BrainBits). In some experiments, chlorophenylthio (CPT)-cAMP (125 $\mu \mathrm{M}$; Sigma) was also present. Added growth factors included BDNF (100 ng/ml; gift from Regeneron), IGF1, IGF2 (both at $50 \mathrm{ng} / \mathrm{ml}$; Peprotech), CXCL12, and PTN (both at $100 \mathrm{ng} / \mathrm{ml}$; Peprotech). In some experiments, bovine insulin (Sigma) was substituted for IGF1 at $5 \mu \mathrm{g} / \mathrm{ml}$. Cells were maintained in $37^{\circ} \mathrm{C} 10 \% \mathrm{CO}_{2}$ incubators and fed with $50 \%$ replacement fresh media every $3 \mathrm{~d}$ in vitro (DIV).

Endothelial cell purification and culture. Endothelial cells were purified from the cerebral cortex of p20 of rats through modification of methods described previously (Mi et al., 2001; Cahoy et al., 2008). Briefly, the cerebral cortices of rats were dissected out of the skull and the meninges were removed with forceps. Tissue was diced using a scalpel blade, and then dissociated with an enzymatic solution of papain $(5 \mathrm{U} / \mathrm{ml}$; Worthington, 3126) containing L-cysteine $(0.4 \mathrm{mg} / \mathrm{ml}$; Sigma, C 7477) and DNase $\left(125 \mathrm{U} / \mathrm{ml}\right.$; Worthington, LS002007) for $20 \mathrm{~min}$ at $35^{\circ} \mathrm{C}$. The tissue was then triturated with $5 \mathrm{ml}$ pipette tips in a solution containing ovomucoid (2 mg/ml; Roche), DNase (125 U/ml), and BSA (1 mg/ml; Sigma) to generate a cell suspension, which was recovered by centrifugation. Endothelial cells were purified by incubation of the cell suspension in a series of mouse anti-CD45 (Serotec)-coated dishes to deplete microglia, and an anti-platelet-derived growth factor receptor $\beta$ (R\&D Systems)-coated dish to deplete pericytes, followed by selection on an anti-CD31 (Fitzgerald)-coated dish. The endothelial cells were recovered by trypsinization, and plated on Type IV collagen (BD Biosciences)coated coverslips. Purity was measured $2 \mathrm{~h}$ after purification by staining with claudin 5 (Invitrogen) and deemed $>98 \%$ pure claudin $5+$ endothelial cells. Vascular cells were grown in a basal medium containing insulin, pyruvate, glutamine, human transferrin $(100 \mu \mathrm{g} / \mathrm{ml})$, bovine serum albumin $(100 \mu \mathrm{g} / \mathrm{ml})$, putrescine $(16 \mu \mathrm{g} / \mathrm{ml})$, progesterone $(60$ $\mathrm{ng} / \mathrm{ml})$, sodium selenite $(40 \mathrm{ng} / \mathrm{ml}), \mathrm{N}$-acetyl cysteine, forskolin, and antibiotics, with basic FGF and $0.5 \%$ FCS for 2 weeks. Puromycin (1 $\mu \mathrm{g} / \mathrm{ml}$ ) was added for the first $3 \mathrm{~d}$ to eliminate nonendothelial cell contaminants.

After 2 weeks in culture to allow the endothelial cells to grow to confluency, the cells were rinsed, and basal serum-free CSMN medium containing CPT-cAMP was added to the wells. After $2-3 \mathrm{~d}$, the ECM was collected, transferred to a Vivaspin $5 \mathrm{kDa}$ molecular weight cutoff filter (Vivascience), and concentrated by centrifugation at $4^{\circ} \mathrm{C}, 2000 \mathrm{rcf}$ until one-tenth of the original volume. The $10 \times \mathrm{ECM}$ was then immediately added to CSMNs at 1:10 (e.g., $10 \mu \mathrm{l}$ of $10 \times \mathrm{ECM}$ plus $100 \mu \mathrm{l}$ of CSMN medium).

Viability and morphology assays. Viability of cultured CSMNs and RGCs was assessed using the LIVE/DEAD Viability/Cytotoxicity Kit (Invitrogen), following the manufacturer's instructions, in which live cells are labeled by their ability to enzymatically convert calcein AM to fluorescent calcein, and dead cell nuclei are labeled with ethidium homodimer-1. Cells were visualized on a Nikon Eclipse TS100 inverted fluorescence microscope and pictures taken with a SPOT-RT digital camera (Diagnostic Instruments) using SPOT software (Diagnostic Instruments). Images were further analyzed for process extension and branching with MetaMorph software (Molecular Devices). For morphology assays, images of $>20$ live cells/condition were analyzed. For survival assays, at least 200 cells per condition were counted and viability was calculated as the percentage of live cells over total cells.

Cryosectioning and immunohistochemistry. At specified time points, rat pups were lethally anesthetized with ketamine/xylazine and then fixed by transcardial perfusion with $4 \%$ paraformaldehyde using a perfusion pump. After fixation, the brains or retinas were removed and postfixed by immersion in $4 \% \mathrm{PFA}$ for $2 \mathrm{~h}$ at $4^{\circ} \mathrm{C}$. Tissue was then equilibrated in $30 \%$ sucrose in PBS overnight at $4^{\circ} \mathrm{C}$, mounted in a sucrose/OCT solution consisting of 2 parts $30 \%$ sucrose/ 1 part Tissue-Tek OCT Compound (Sakura Finetek), frozen using dry ice or liquid nitrogen, and stored at $-80^{\circ} \mathrm{C}$ until cryosectioning. Sections ( $14 \mu \mathrm{m}$ thick) were generated on a Leica CM3050 cryostat and mounted on slides. Immunostained slides were blocked for $30 \mathrm{~min}$ at room temperature in $50 \%$ normal goat serum in antibody buffer containing $\mathrm{NaCl}(150 \mathrm{~mm})$, Tris Base (50 mM) (both from Fisher Scientific), L-lysine (100 mM), 1\% BSA (both from Sigma), $0.04 \%$ sodium azide, and $0.4 \%$ Triton X-100 to permeabilize cell membranes. Sections were then incubated overnight at $4^{\circ} \mathrm{C}$ in antibody buffer containing 1:500 anti-COUP-TF-interacting protein 2 (anti-CTIP2) antibody (ab18465; Abcam). Finally, slides were incubated for $1 \mathrm{~h}$ at room temperature in the dark in antibody buffer containing 1:500 Alexa Fluor 594 goat anti-rat secondary antibody (A11007; Invitrogen). Slides were mounted using a PBS-glycerol-based mount [VectaShield mounting medium with 4',6'-diamidino-2phenylindole dihydrochloride (DAPI); Vector Laboratories]. Sections were examined and imaged on a Nikon Eclipse E800 fluorescence microscope as described above.

Immunocytochemistry. Cells cultured on glass coverslips were immunostained by fixing for $10 \mathrm{~min}$ in 4\% PFA, then blocking for $30 \mathrm{~min}$ in $50 \%$ goat serum in antibody buffer with Triton X-100 as described above. Coverslips were incubated overnight at $4^{\circ} \mathrm{C}$ in antibody buffer containing 1:500 anti-MAP2 antibody (M1406; Sigma) and 1:500 anti-CTIP2 antibody. Finally, coverslips were incubated for $2 \mathrm{~h}$ at room temperature in the dark with antibody buffer containing 1:1000 Alexa Fluor 488 goat anti-mouse secondary antibody (A-11001; Invitrogen) and 1:1000 Alexa Fluor 594 goat anti-rat secondary antibody (A-11007; Invitrogen), then mounted on slides using Vectashield plus DAPI (Vector Laboratories) and imaged as described above.

RNA purification, amplification, and gene chip hybridization. Total RNA was isolated from acutely purified cells with the RNeasy Micro kit (Qiagen), using Qiashredder columns for cell lysis and inserting Qiagen on-column DNase steps to remove any contaminating genomic DNA. CSMNs from P3 and P7 rat pups were purified as described above. For the whole-brain sample, one litter of P3 mice were injected and subsequently subjected to the same purification protocol as for CSMNs, but following the BSLI-plate panning steps, the entire nonadherent cell suspension was collected. The vascular cell samples were prepared as described previously (R. Daneman, L. Zhou, and B. A. Barres, unpublished observation). Briefly, vascular cells were FACS sorted from transgenic homozygous Tie2GFP mice (strain 003658), obtained from Jackson Laboratories, in which all endothelial cells express green fluorescent protein (GFP). For brain samples (adult and first postnatal week), the cerebral cortex was dissected away from the forebrain, then the meninges were peeled off with fine forceps. For the adult liver, the periphery of each lobe was dissected and used as to avoid the hepatic portal vein; thus, the tissue used had vasculature consisting primarily of sinusoidal capillaries. For the adult lung, whole-lung lobes were used. Each tissue was diced with a scalpel, and enzymatically dissociated as described previously to yield a total cell suspension that was subsequently recovered by centrifugation. Cell suspensions were resuspended in FACS buffer (Dulbecco's PBS, 0.02\% BSA with propidium iodide), and endothelial cells (and tightly associated pericytes) were FACS purified based on GFP fluorescence using a FACS Vantage SE sorter (Becton Dickinson) and CellQuest software.

For each sample, $\sim 30$ ng of total RNA was amplified and labeled by Affymetrix Two-Step Labeling Kit protocols. Fragmented, biotin-labeled cRNA was then applied to Affymetrix Rat Genome 2302.0 arrays (CSMN and whole-brain samples) or Mouse Genome 4302.0 arrays (vascular samples) at the Stanford Protein and Nucleic Acid Biotechnology Facility according to Affymetrix protocols. Expression data were generated from chip scans using Affymetrix GeneChip operating software.

\section{Results \\ Development of a new method for purification of specific populations of CNS neurons}

Cholera toxin is the pathologically active agent secreted by the bacterium Vibrio cholerae, and is composed of two subunits, A 
and $\mathrm{B}$. The A subunit is the toxic part, whereas the pentameric B subunit is nontoxic and is required for the binding of cholera toxin to its cell-surface receptor, ganglioside GM1 (Spangler, 1992), a ubiquitous membrane component expressed in both neurons and glia in the adult CNS (Cuatrecasas, 1973). The CTB is internalized by cell processes via its binding to GM1 (Chinnapen et al., 2007), then retrogradely transported back to the cell body, where CTB has been shown to recycle back to the cell surface (Nickel, 2005; Pelkmans and Zerial, 2005). CTB is commonly used as a retrograde tracer because of its high sensitivity, rapid axonal transport, and stability in neurons (Oudega et al., 1994). The properties of CTB suggested that we could use retrograde CTB labeling to insert a cell-surface marker that would be specific for only that labeled cell population. We wanted to investigate whether the presence of CTB at the cell surface could be used to purify populations of neurons via immunopanning. To do this, we modified an immunopanning technique first developed for the purification of RGCs (Barres et al., 1988).

In our initial experiments, we used Alexa 488- or Alexa 594conjugated CTB molecules to retrogradely label RGCs, and subsequently purified the cells by incubation with a monoclonal antibody to CTB. Although we were able to highly purify the RGCs from a retinal cell suspension, our yields were low. This was likely because of the enzymatic digestion of cell-surface CTB by papain during the dissociation step, leaving only a minor amount of nonproteolytically cleaved CTB available for immunopanning. To increase the amount of CTB recycled from intracellular stores back to the cell surface after papain treatment, we retrogradely labeled RGCs with CTB-coated fluorescent Retrobeads IX. It has been shown previously that these beads are nontoxic, and that they gradually release various growth factors adsorbed to their surface over several days (Katz et al., 1984; Riddle et al., 1995, 1997). We therefore reasoned that injection of CTB-coated Retrobeads would generate retrogradely labeled cells with increased intracellular stores of CTB, which would be protected from proteolytic papain digestion during tissue dissociation. This adjustment greatly improved our yields (Fig. 1A).

\section{CTB panning of RGCs is comparable with established protocols for RGC isolation by panning}

To address the question of whether CTB can be used to immunopurify retrogradely labeled neuronal populations, we first investigated this possibility in RGC neurons, which we routinely purify via immunopanning using antibodies directed against the RGC-specific surface epitope Thy1.1 (Barres et al., 1988). RGCs were retrogradely labeled by injecting CTB adsorbed to fluorescent Retrobeads into the superior colliculi (Fig. $1 B$ ). Numerous RGCs were fluorescently labeled $48 \mathrm{~h}$ after injection of the tracer (Fig. 1C). At that time point, fluorescently labeled retinas were dissected and a single-cell suspension was generated. After dissociation, the cell suspension was applied to BSLI-coated panning dishes to remove microglial cells before incubation of the cell suspension on the final anti-CTB-coated panning dish. This was necessary because microglial cells could potentially bind nonspecifically to the final panning dish via their expressed Fc receptors (Reichert and Rotshenker, 1996). Also, microglia have high levels of GM1 (Nedelkoska and Benjamins, 1998), and therefore could pick up CTB released by lysed cells, which would enhance their binding to the final panning dish. Microglia bind with high affinity to BSLI (Streit and Kreutzberg, 1987; Kaur et al., 1990; Kaur and Ling, 1991), and therefore can be efficiently removed from the cell suspension before the final panning dish, eliminating this potential problem.
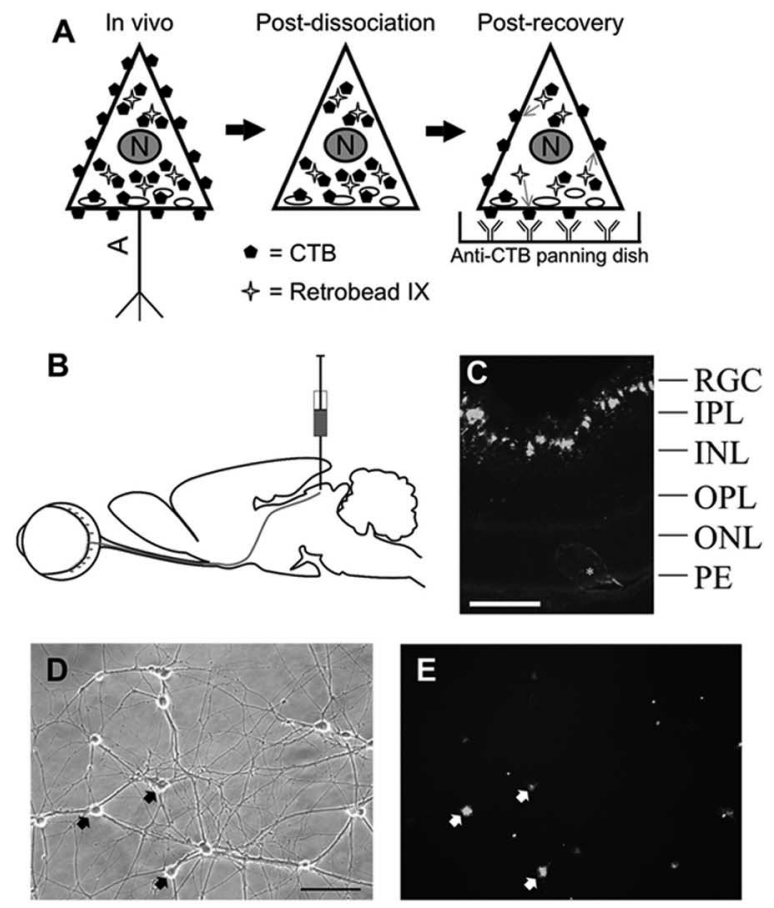

$\mathbf{F}$

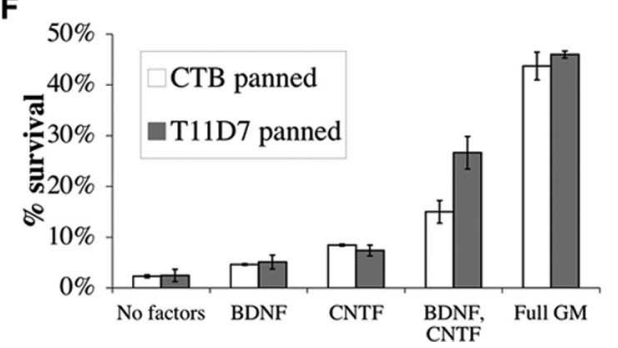

Figure 1. CTB panning can be used to purify RGCS.A, Retrogradely transported CTB is cleaved from the surfaces of labeled cells during enzymatic dissociation, but internal stores of $C T B$ bound to Retrobeads IX replace lost CTB during the postdissociation recovery step and can then be selectively bound by immunopanning. N, Nucleus; $A$, axon. $B$, CTB conjugated to fluorescent tracer Retrobeads injected into the superior collicular brachium is retrogradely transported to the retina. C, Fluorescent tracer is localized to the RGC layer in the retina $48 \mathrm{~h}$ after the injection. Scale bar, $100 \mu \mathrm{m}$. RGC, RGC layer; IPL, inner plexiform layer; INL, inner nuclear layer; OPL, outer plexiform layer; $\mathrm{ONL}$, outer nuclear layer; $\mathrm{PE}$, pigmented epithelium. $\boldsymbol{D}$, Phase-contrast image of (TB-panned RGCs in culture. Scale bar, $100 \mu \mathrm{m}$. $\boldsymbol{E}$, Fluorescent image of the same field shows that purified RGCs are fluorescently labeled with Retrobeads (arrows). $\boldsymbol{F}$, Retrogradely labeled RGCs that adhere to the CTB panning plate (CTB panned) and RGCs purified from unlabeled retinas by Thy1.1 antibody (T11D7 panned) respond similarly to BDNF, CNTF, and full growth medium (BDNF, CNTF, insulin, and forskolin). Survival of RGCs purified from $\mathrm{P} 6$ rats assayed after 3 DIV ( \pm SEM) is shown ( $n=2 ;>150$ cells/replicate condition scored).

After removal of microglia from the cell suspension, retrogradely labeled RGCs were selected by their binding to a CTBspecific antibody-coated panning plate. Purified RGCs survived and extended neurites under standard RGC growth conditions (Fig. $1 D, E$ ). The cell suspension that did not adhere to the antiCTB panning dish was transferred to a panning dish coated with anti-Thy1.1 antibody (T11D7 clone). By comparing the number of cells attached to the anti-CTB dish to those attached to the T11D7 dish, we determined that the anti-CTB panning dish was able to purify $\sim 30 \%$ of all RGCs that could possibly be panned from retinas isolated from rat pups at P6 (Table 1). This ratio is reduced at later developmental time points $(22.5 \%$ at P8 and $15.1 \%$ at P10). These data demonstrate that CTB-labeled RGC neurons can be efficiently purified by immunopanning using a CTB-specific antibody. 
Table 1. Percentage RGCs purified by CTB immunopanning

\begin{tabular}{lclll}
\hline Age & CTB panning & T11D7 panning & Total RGCs & Total CTB panned \\
\hline P6 & 166,000 & 380,000 & 546,000 & $30.4 \%$ \\
P8 & 45,000 & 155,000 & 200,000 & $22.5 \%$ \\
P10 & 63,000 & 353,000 & 416,000 & $15.1 \%$ \\
\hline
\end{tabular}

There have been several reports describing the effect of CTB on neurite outgrowth and responses to neuronal growth factors (Doherty and Walsh, 1987; Masco et al., 1991; Mutoh et al., 1993; Wu et al., 1994). Therefore, we wanted to address whether CTB labeling of RGC neurons interferes with the cellular functions of RGCs. We first compared the response to growth factors of antiCTB- and T11D7-panned cells. Both groups of RGCs responded similarly to RGC survival factors ciliary neurotrophic factor (CNTF) and BDNF, and also our previously characterized "full" RGC growth medium containing BDNF, CNTF, insulin, and the cAMP-elevating compound forskolin (Fig. $1 F$ ). We were also unable to detect significant differences between the abilities of anti-CTB- and T11D7-panned neurons to extend neurites and generate synapses (supplemental Figs. S1, S2, available at www. jneurosci.org as supplemental material). Cumulatively, these data demonstrate that retrograde labeling of neurons with CTB bound to Retrobeads enables the targeted neurons to be highly purified via immunopanning without adversely affecting their viability or other normal cellular processes.

\section{Early postnatal rat CSMNs can be purified to $99 \%$ purity with CTB panning}

We next sought to use this method to purify CSMNs from neonatal rat pups. We injected CTB conjugated to fluorescent Retrobeads into the pyramidal decussation of the spinal cord of rat pups at P1 (Fig. $2 A$ ). After waiting $2 \mathrm{~d}$ for the label to be retrogradely transported to the cortex, the pups were killed, the cortex was dissected, and then gently dissociated. Only cortices that were detectably labeled were included in the dissociations (Fig. $2 B, C)$. To improve our yield of CSMN neurons, we modified our dissociation buffers by replacing sodium chloride with sucrose. Dissection and dissociation in iso-osmolar sucrose solution has been found to improve the health of motoneurons (Aghajanian and Rasmussen, 1989). It is thought that passive chloride entry during dissociation has an acute neurotoxic effect, leading to cell swelling and lysis of neurons; by eliminating sodium chloride in the buffer, this was prevented. This simple modification increased our yields and improved the health of acutely purified neurons to $>90 \%$ viability after initial dissociation (data not shown).

Once purified, dissociated cells were plated at a density of 35 cells $/ \mathrm{mm}^{2}$ and cultured for 1-9 DIV. Purifications performed at P3 typically gave a final yield of $9510 \pm 2590$ SD (CSMNs/brain; $n=19$ ). Yields were similar for purifications performed at P4-P5 (data not shown), but dropped off sharply for older rats. Purifications performed at P7 produced only $3000 \pm 600$ SD (CSMNs/ brain; $n=7$ ), and purifications attempted at P10 yielded very few neurons (data not shown).

To verify that purified cells were CSMNs, we first immunostained cortical slices with CTIP2, a transcription factor that has been found to be specifically expressed by layer $\mathrm{V}$ cortical cells (Arlotta et al., 2005; Molyneaux et al., 2007) (Fig. 2D,E). AntiCTIP2 was localized exclusively to the nuclei of layer $\mathrm{V}$ cells. Green fluorescent microbeads were seen in the cell bodies and neurites of layer $\mathrm{V}$ cells, but not elsewhere, demonstrating that our technique specifically labels layer V neurons. All fluores- cently labeled cells costained with CTIP2, although not every CTIP2-positive cell was labeled with microbeads. Second, we verified that our CTP-immunopanned cell cultures were pure CSMNs by costaining the cultured cells with anti-CTIP2 and a neuronal marker, anti-MAP2 (Fig. 2F). We observed a 100\% correlation between anti-MAP2 and anti-CTIP2 cell staining, indicating that all isolated neurons were CSMNs. Cultures were also stained with DAPI nuclear stain; almost all DAPI nuclei costained with CTIP2 $(99.1 \% \pm 1.1 \%$ SD $)$. Therefore, isolated cultures are $99.1 \%$ pure CSMNs.

\section{Genomic expression analysis to confirm purified CSMN identity}

We next compared the pattern of gene expression in our purified P3 CSMNs to gene expression in the whole dissociated brain by Affymetrix Rat Genome 2302.0 array hybridization (supplemental Table S1, available at www.jneurosci.org as supplemental material). We found that our population of purified CSMNs expressed several standard neuronal markers, as expected (Fig. $3 A$, supplemental Table S2, available at www.jneurosci.org as supplemental material). Furthermore, we observed that, relative to the whole-brain sample, our purified CSMNs expressed minimal levels of all the astrocyte, oligodendrocyte/oligodendrocyte precursor cell, and vascular cell markers we analyzed. These data confirmed that our method had successfully isolated a highly pure population of neurons. Similar results were observed for CSMNs purified from $\mathrm{P} 7$ rats, although the population appeared to be slightly less pure than the $\mathrm{P} 3$ preparation (supplemental Table S1, available at www.jneurosci.org as supplemental material).

To analyze the identity of the neurons we had purified, we determined the expression of genes reported previously to be specific for CSMNs (crim1), genes reported to be specific for layer $\mathrm{V}$ subcerebral projection neurons, which include CSMNs (bcl11b, fezf2, ldb2, S100a10 and pcp4), and genes reported to be enriched in layer V (contactin 6 and cadherin 13) (Arlotta et al., 2005; Molyneaux et al., 2007). Most were highly expressed relative to average gene expression levels in our purified population (supplemental Table S2, available at www.jneurosci.org as supplemental material). When we compared the expression levels in our purified cells to the expression levels found in whole cortex, these CSMN-specific genes were generally enriched in our purified cells (Fig. 3B, supplemental Table S2, available at www. jneurosci.org as supplemental material), providing additional evidence that our protocol successfully purified CSMNs from total neurons.

\section{In vitro survival of purified CSMNs is enhanced by the presence of antioxidants and CAMP}

We cultured purified CSMNs in defined, serum-free media. In initial experiments, we supplemented the media with B27, a chemically defined serum replacement mixture allowing high neuronal survival and reduced glial growth (Brewer et al., 1993). To determine the contribution of B27 to the short-term survival of CSMNs, we also excluded B27 from the growth medium, added B27 without antioxidants, or added antioxidants only (SCAVEGR supplement; BrainBits). Short-term survival of CSMNs was almost zero in the absence of B27 or in the presence of B27 without antioxidants, whereas antioxidants (SCAVEGR) alone had the same beneficial effect on short-term survival as B27 (data not shown). Therefore, in all of the subsequent experiments described below, we supplemented our growth medium with SCAVEGR instead of B27.

In addition, we tested whether increasing intracellular levels 

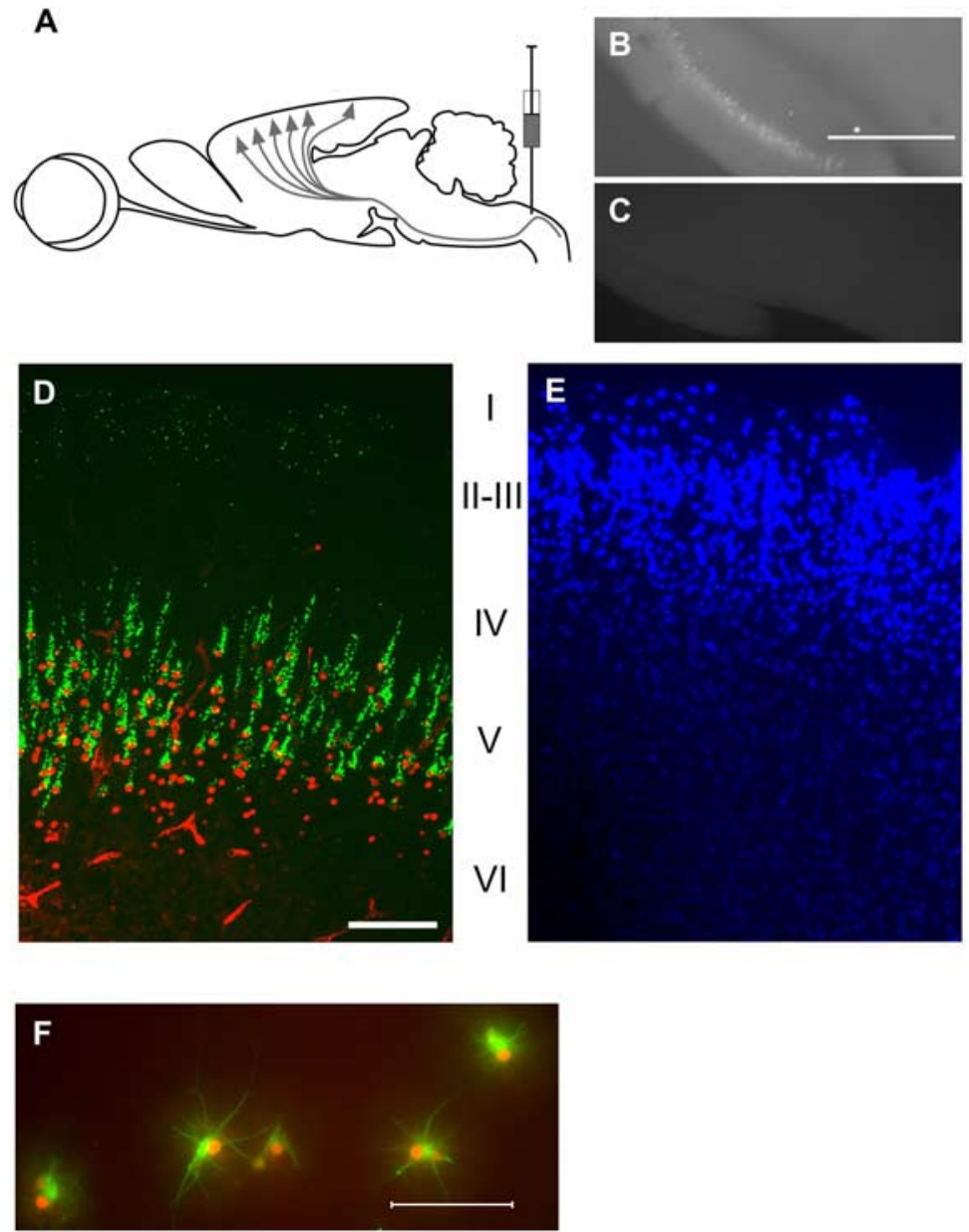

Figure 2. CSMNs can be purified by CTB panning. $A$, CTB conjugated to fluorescent tracer Retrobeads is injected into the pyramidal decussation of the spinal cord and retrogradely transported to cortical layer V. $\boldsymbol{B}, \boldsymbol{C}$, Successfully retrogradely labeled dissected cortices $(\boldsymbol{B})$ can easily be discerned from unsuccessful injections that fail to label layer $V(\boldsymbol{C})$ using an inverted fluorescent microscope. $\boldsymbol{D}, \boldsymbol{E}$, Immunohistochemistry shows that cells labeled with green fluorescent Retrobeads are layer V CSMNs. All retrogradely labeled (green) cells also label with CTIP2 (red), a nuclear marker for CSMNs (D). Blue DAPI costain shows that CTIP2 is specific for layer $V$ cells $(\boldsymbol{E}) . \boldsymbol{F}$, Immunocytochemistry of cultured purified cells shows that they are CSMNs. All purified cells labeled by neuronal marker MAP2 (green) coexpress CTIP2 (red). Scale bars: (in $\boldsymbol{B}) \boldsymbol{B}, \boldsymbol{C}, 1 \mathrm{~mm}$; $\boldsymbol{D}$ (for $\boldsymbol{D}, \boldsymbol{E}$ ), $\boldsymbol{F}, 100 \mu \mathrm{m}$. post hoc Student-Newman-Keuls test). In addition, we observed a similar increase in neuronal process outgrowth and complexity (branching) in cells cultured in the presence of BDNF (Fig. 5C) or IGF1 (data not shown) relative to surviving cells in CPT-cAMP-only controls (Fig. 5B, $G, H$ ). These data confirm that the trophic responsiveness of the cells we have isolated via our novel CTB immunopanning method conform to the previously reported behavior for purified CSMNs.

To further examine the survival requirements of the purified CSMNs, we performed a more detailed analysis of the ability of IGF1 and BDNF to promote viability of CSMNs over time in vitro. In these experiments, $5 \mu \mathrm{g} / \mathrm{ml}$ insulin, which stimulates IGF1 receptors at high concentrations (Schumacher et al., 1993), was substituted for IGF1. We consistently found that the survival of purified P3 CSMNs steadily declined over time in either medium containing only insulin, or insulin plus BDNF (Fig. 4B1,B2). Similar results were obtained when we purified CSMNs from P7 rats, although their survival appeared to decline more rapidly than the CSMNs obtained from younger rats (Fig. $4 C)$. These data indicate that the previously characterized CSMN growth factors IGF1 and BDNF can enhance the viability of our CTB-immunopurified CSMNs, but that they are insufficient to fully support the long-term survival of these cells.

Genomic expression analysis shows that P3 and P7 CSMNs express many receptors for growth factors secreted by brain endothelial cells

To identify potential further, possibly preof cAMP could enhance CSMN viability. CPT-cAMP was added to mimic the effects of electrical excitation by raising cAMP levels, which has been shown previously to be crucial to enhancing CNS neuron responsiveness to trophic factors (Meyer-Franke et al., 1995; Hanson et al., 1998; Meyer-Franke et al., 1998). Addition of CPT-cAMP alone to purified cultures of CSMNs was sufficient to significantly enhance survival (Fig. $4 A$ ), from 15 to $24 \%$ over 5 DIV ( $p<0.0001$, two-tailed Student's $t$ test). CPT-cAMP was therefore included in all of our CSMN survival assays when testing added trophic factors or conditioned medium.

\section{In vitro survival of purified CSMNs is enhanced by the presence of BDNF and IGF1, but these factors are not sufficient to support long-term survival}

To investigate the trophic factor requirements of CSMNs, we began by determining the effectiveness of the previously characterized CSMN survival factors BDNF and IGF1 (Giehl et al., 1998; Hammond et al., 1999; Schütte et al., 2000; Giehl et al., 2001; Lu et al., 2001; Ozdinler and Macklis, 2006) at promoting purified CSMN viability. We found that both factors could reproducibly increase CSMN 5 DIV survival by a small but significant amount (Fig. 4A) (1.25-fold increase from 24 to 30\%; $p<0.001$ ANOVA viously unrecognized, sources of trophic support for CSMNs, we decided to analyze the gene chip data we had generated to determine whether we could identify additional growth factor receptors that are robustly expressed by CSMNs. Knowing that BDNF and IGF1 could enhance CSMN viability, we began by determining the expression levels of other trophic factor receptors belonging to these families. We found that the BDNF receptor, NTRK2, was apparently the most robustly expressed member of the tyrosine receptor kinase family of receptors (supplemental Table S1, available at www.jneurosci.org as supplemental material). When we compared the expression levels of the IGF receptors, however, we found that IGF2R was expressed at least the same level as IGF1R. We therefore decided to examine the ability of IGF2 to further support CSMN survival.

To identify additional potentially uncharacterized CSMN trophic factor receptors, we analyzed the list of genes that were expressed at a level at least threefold higher than the average level across the entire gene array (731 arbitrary units). We found that the receptors for known growth factors such as CXCL12 $(\mathrm{SDF} 1 \alpha), \mathrm{PTN}$, transforming growth factor $\beta$ (TGF $\beta)$, and semaphorin $7 \mathrm{a}$ (Sema7a) were highly expressed, typically at levels of 3000 (Table 2). In comparison, the expression level of the BDNF 
receptor, NTRK2, in purified CSMNs was 1896, and the receptor for IGF1 was expressed at a level of only 211, both lower than the levels for the several growth factor receptors described above.

To confirm the layer $\mathrm{V}$ expression of many of the receptors listed in Table 2, we examined the in situ hybridization data for these genes in the Allen Brain Atlas, and found that several of these receptors did appear to be expressed in layer V (supplemental Fig. S3, available at www. jneurosci.org as supplemental material). Interestingly, we noticed that most of the growth factor ligands of the receptors listed above are highly expressed by vascular cells in the brain as shown by gene chip analysis of purified brain endothelial cells (ECs) and pericytes (Daneman, Zhou, and Barres, unpublished observation) (Table 2 ), and that several of these factors appeared to be most highly produced by the vascular cells of the CNS relative to nonneural vasculature (supplemental Table S3, available at www.jneurosci.org as supplemental material). This raised the intriguing possibility that vascular cells may be providing trophic support to CSMNs in the CNS.

Brain endothelial cells help support the survival and growth of purified CSMNs To test whether brain vascular cells could support CSMN survival, we began by purifying and culturing brain ECs from postnatal rats. Via immunopanning for CD31, we were able to obtain cultures of brain ECs that were $>98.5 \%$ pure, as assayed by claudin 5-positive immunoreactivity (data not shown). These cells were maintained in $0.5 \%$ serum-containing media for 2-3 weeks in vitro until nearly confluent, at which point the cells were thoroughly rinsed to remove traces of serum, and then incubated for 2-3 DIV in the same basal serum-free medium formulation (plus CPT-cAMP; no growth factors) used for CSMN cultures. The serum-free ECM was then collected and concentrated 10-fold by centrifugation through a $5 \mathrm{kDa}$ molecular weight cutoff filter, which should retain any large protein trophic factors secreted into the medium by ECs. Concentrated $10 \times$ ECM was immediately added at a 1:10 ratio to fresh cultures of pure CSMNs that had been plated in medium containing only CPT-cAMP with no additional growth factors.

We found that the addition of ECM significantly increased the viability of pure cultured CSMNs (Fig. $4 A$ ). In addition, we observed that the surviving CSMNs cultured in the presence of ECM in general looked much healthier, extending a greater number of more highly branched processes than CSMNs surviving in CPTcAMP-only medium, or even CSMNs cultured with BDNF (Fig. $5 B, C, F)$. These data indicate that brain ECs represent an undera-
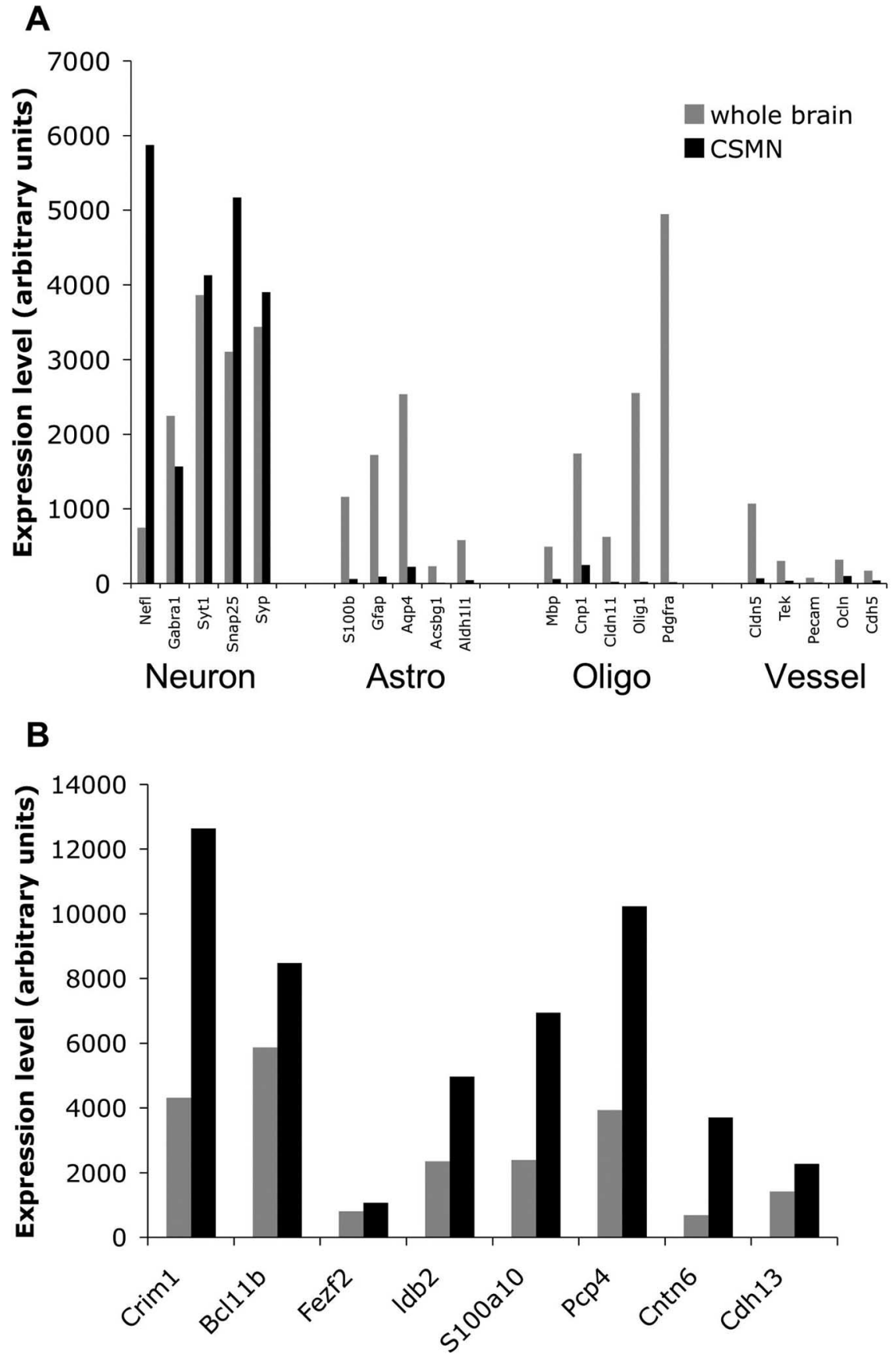

Figure 3. Purified CSMNs express CSMN and neuronal genes and not other neural genes. $A, B$, Comparison of expression levels of stereotypical neuronal, astrocyte, oligodendrocyte/oligodendrocyte precursor cell, and vascular cell ( $\boldsymbol{A}$ ) and CSMN-enriched (B) genes in purified CSMNs (black) and whole dissociated brain (gray) from P3 rats. Probe sets and expression values (arbitrary units) are shown in supplemental Table S2 (available at www.jneurosci.org as supplemental material). In cases where multiple probe sets are present for a single gene, the probe set with the highest expression was chosen. To fit the graph, the expression values for Syt 1 and Snap 25 were scaled down threefold for both samples.

ppreciated, potentially potent source of trophic support for CSMNs.

Factors produced by brain endothelial cells, IGF2, CXCL12, and PTN have comparable survival activity to BDNF and IGF1 for cultured CSMNs

After finding that brain ECs could support CSMN survival, we next wanted to determine whether individual growth factors that are highly expressed by ECs could similarly enhance CSMN viability. To determine whether these EC-secreted proteins could 
A

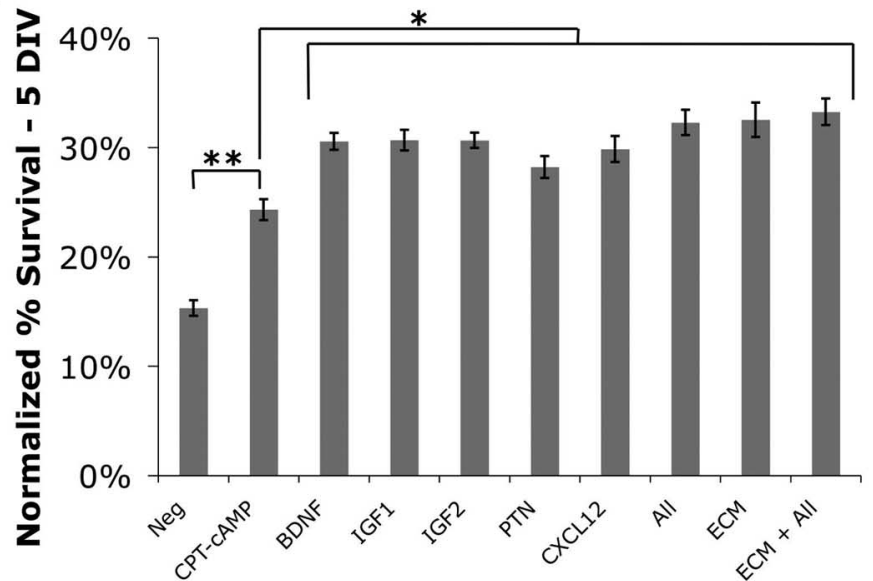

B1

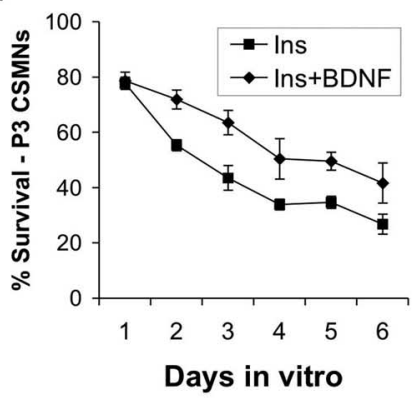

C

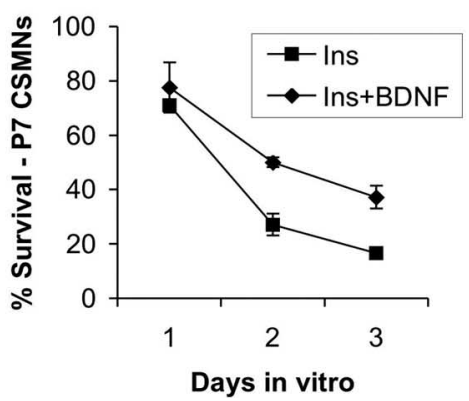

Figure 4. Survival of CTB-immunopurified CSMNs in vitro. A, Percentage of purified P3 CSMNs surviving after 5 DIV in the various media listed. Neg, Basal serum-free medium (see Materials and Methods); (PT-cAMP, (PT-cAMP added to basal medium; all remaining single/multiple factors were added in the presence of CPT-CAMP; All, CXCL12 plus IGF2 plus PTN plus BDNF with or without IGF1 (no significant differences noted with/without IGF1 when the other four factors were present); ECM, fresh 10XECM added at plating and day 3 feeding. All data presented were normalized to negative controls (Neg or CPT-CAMP) ( \pm SEM). ${ }^{*} p<$ 0.001 , multiple pairwise ANOVA post hoc Student-Newman-Keuls test; ${ }^{* *} p<0.0001$, two-tailed Student's $t$ test; all statistical differences were found with control CPT-CAMP, no significant differences were detected between the various factor/ECM conditions. Neg, $n=20 ;$ CPT-CAMP, $n=41 ; \mathrm{BDNF}, n=33 ; \mathrm{IGF1}, n=21 ; \mathrm{IGF}, n=33 ; \mathrm{PTN}, n=26 ; \mathrm{CXCL} 12, n=15 ; \mathrm{All}, n=19 ; \mathrm{ECM}$, $n=11 ; \mathrm{ECM}+$ All, $n=13$; for each " $n$ " value, $50-300$ cells per well were counted. $\boldsymbol{B} 1, \mathbf{B} 2$, Insulin + BDNF supports short-term but not long-term CSMN survival. Two independently performed assays of purified P3 CSMN survival at various DIV in media containing CPT-CAMP and insulin, with or without BDNF are shown. All data are \pm SEM $(n=3)$. C, Survival of purified P7 CSMNs 1-3 DIV in media containing CPT-CAMP and insulin, with or without BDNF.

support CSMN survival, we cultured purified CSMNs for 5 DIV in the presence of IGF2, CXCL12, or PTN. We found that all three were individually able to promote CSMN survival similar to the levels observed for BDNF and IGF1 (Fig. 4A). We also assessed the morphology of the surviving cells and found that IGF2 (Fig. 5D), CXCL12, and PTN (data not shown) could all increase CSMN total process outgrowth and branching to a similar or even slightly greater degree than BDNF (Fig. $5 C, G, H$ ) or IGF1 (data not shown). When we combined IGF2, CXCL12, PTN, and BDNF all together, we observed only a slight enhancement of
CSMN survival relative to single growth factors (Fig. 4A). We also noted that adding IGF1 to this mix did not further increase CSMN viability (data not shown). Interestingly, whereas a mixture of CSMN trophic factors did not greatly increase the long-term survival of the purified CSMNs, exposure to multiple ECM-derived trophic factors plus BDNF did enhance the process extension and branching of the surviving cells over the levels observed for single trophic factors (Fig. 5C-E,G,H). Consistent with the hypothesis that brain ECs support CSMN viability by secreting IGF2, CXCL12, and PTN, we found that addition of these factors, either alone or in combination with BDNF and IGF1, to $10 \times$ ECM did not further enhance the ability of ECM to support CSMN survival (Fig. 4A). We also observed no significant difference between the morphology of CSMNs cultured in the presence of ECM (Fig. $5 F$ ), a mixture of IGF2, CXCL12, PTN, and BDNF (Fig. $5 E$ ), or ECM plus the trophic factor mixture (data not shown). Cumulatively, these data indicate that brain EC-secreted IGF2, CXCL12, and PTN are likely an important, previously unidentified source of trophic support for CSMNs.

\section{Discussion}

Development of a novel method for purification of CNS projection neurons CTB immunopanning is a novel neuron purification method that allows projection neurons to be retrogradely labeled with CTB and then purified by immunopanning with an anti-CTB antibody. We have demonstrated the utility of this method for purifying two different populations of CNS neurons, RGCs and CSMNs. Thanks to the ubiquitous expression of GM1 by central neurons (Cuatrecasas, 1973), this method should be broadly applicable, allowing for the purification of any CNS neuron population that can be selectively retrogradely labeled within a structure that can be subsequently grossly dissected out of the CNS. Although we have focused on its usefulness for purifying defined types of rodent neurons, in principle it should also work in larger mammals such as ferrets or primates.

We found that our CTB panning procedure seems to produce higher yields than comparable FACS purification procedures for the same cell population. FACS purification of mouse CSMNs produces yields of $\sim 1000$ CSMNs/ brain at P4 (Arlotta et al., 2005; Ozdinler and Macklis, 2006). Because mouse cortex has on average $\sim 44 \%$ as many neurons as rat cortex (Herculano-Houzel and Lent, 2005; HerculanoHouzel et al., 2006), if this same scaling applies to the CSMN population, then 1000 mouse CSMNs would correlate to $\sim 2270$ rat CSMNs. In comparison, the CTB panning purification yields 
9000 CSMNs/brain at P3, an increase of approximately fourfold over FACS yields. A previous FACS purification protocol for $\mathrm{P} 2$ rat CSMNs reported yields of 4000 CSMNs per brain (Junger and Junger, 1998); again, a yield that is more than twofold lower than that regularly attained with our CTB immunopanning purification. In addition, immunopanning is normally a gentler protocol than FACS-based purification, and therefore our protocol should in general yield neurons with improved initial viability, making them potentially more suitable for subsequent in vitro culturing experiments.

We did find that the efficiency of CTB immunopanning for RGCs was significantly less than the efficiency obtained by panning with the endogenous epitope Thy1.1. There are several possible explanations for this observation. First of all, it is very likely that only a subset of a CTB traced cell population becomes labeled with CTB, because retrograde labeling of axon tracts is usually incomplete, often labeling $<25 \%$ of axons, and the extent of labeling varies widely with each injection (Bareyre et al., 2005). The incomplete labeling of the CSMN population was apparent in our immunostained cortical slices (Fig. 2D). The fact that several RGCs project to the lateral geniculate nucleus instead of the tracerinjected superior colliculus likely also contributes to this incomplete labeling. Furthermore, the level of surface expression of CTB may vary stochastically among the cell population. In any case, the presented procedure in principle greatly broadens the range of CNS neuron types that it is now possible to isolate for molecular and culture studies.

We also noticed a decrease in the amount of neurons that could be purified from retinal and cortical cell suspensions with increasing postnatal age. There may be several explanations for this observation that are not mutually exclusive. First, it is known that the absolute amounts of RGCs and CSMNs in the CNS decline during early postnatal development via programmed cell death (Young, 1984; Gorgels, 1990; Spreafico et al., 1995; Terashima, 1995; Bonfanti et al., 1996). Second, with increasing age, dendritic networks become more complex, which in combination with increases in the amount of connective tissue make it more difficult to generate a single-cell suspension from both retina and cortex, thereby resulting in decreased yields. Third, increased sensitivity to excitotoxicity with increasing age might also contribute to more cell death during our dissociation procedure. These findings highlight the necessity to carefully select an appropriate age for retrograde labeling and subsequent tissue dissociation when using this procedure. In particular, motor neurons appear to be more difficult to isolate with maturation compared with most other neuron types.

\section{cAMP, BDNF, and IGF1 support the survival of CSMNs}

Our novel purification method has allowed us to directly examine the survival requirements of purified CSMNs. We found that in-

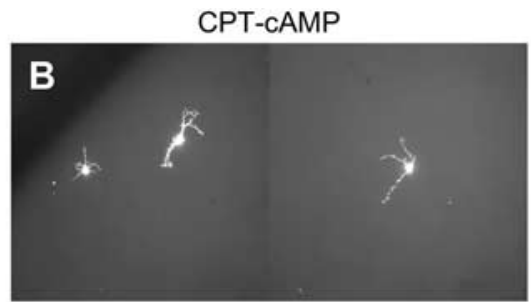

IGF2

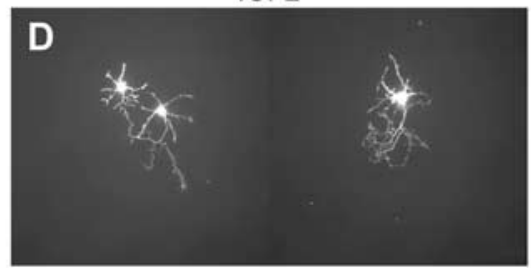

ECM

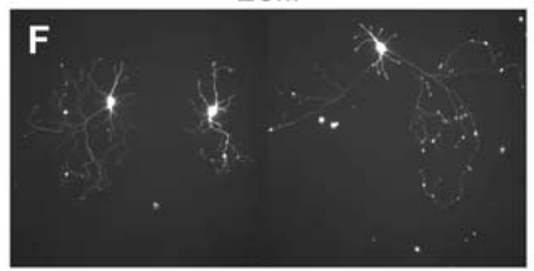

H

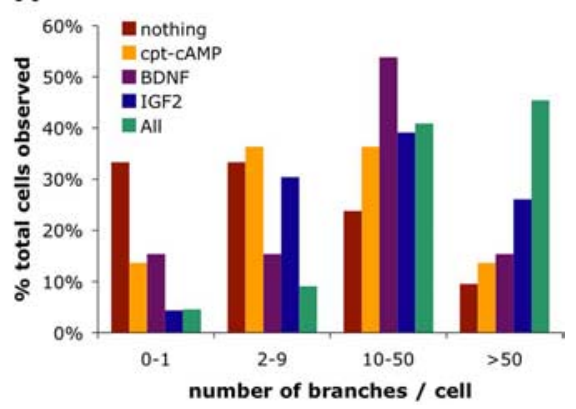

Figure 5. Morphology of CTB-immunopurified CSMNs in vitro. $\boldsymbol{A}-\boldsymbol{F}$, Representative images of purified P3 CSMNs cultured for 5 DIV in basal serum-free medium $(\boldsymbol{A})$, basal media containing (PT-CAMP alone (B), CPT-cAMP plus BDNF (C), IGF2 (D), BDNF plus XCL12 plus IGF2 plus PTN (E), or 10× ECM (F). All live cells were visualized by incubation in calcein AM. Scale bar, $100 \mu \mathrm{m}$. $\boldsymbol{G}, \boldsymbol{H}$ wing percentages of purified $\mathrm{P3}$ CSMNs alive at 5 DIV in indicated media, visualized by calcein AM incubation, demonstrating $<50,50-400,400-800$, or $>800 \mu \mathrm{m}$ total process outgrowth $(G)$, or $0-1,2-9,10-50$, or $>50$ total process branch points $(\boldsymbol{H})$. In each condition, $>20$ randomly selected live cells were analyzed.

creasing intracellular cAMP levels in the absence of peptide trophic factors could enhance CSMN viability. In the past, we and others have found that elevated cAMP levels alone strongly support the survival of some CNS neuron populations (SMNs and callosal projection neurons) (Hanson et al., 1998; Catapano et al., 2001), but not RGCs or cortical neurons in general (Meyer-Franke et al., 1995). Our observations indicate that increasing cAMP in CSMNs can support a low level of viability that is further enhanced by the addition of peptide trophic factors, similar to our previous observations with SMNs. We also confirmed that BDNF and IGF1 were significant survival factors for this population, agreeing with many previous studies (Giehl et al., 1998; Hammond et al., 1999; Schütte et al., 2000; Lu et al., 2001; Ozdinler and Macklis, 2006), and further indicating that we had successfully purified layer V CSMNs. However, in several independent experiments, we found that even BDNF, IGF1, and CPT-cAMP in combination could not support the long-term health of CSMNs in culture. These data indicated that CSMNs likely require additional trophic factors for their sustained survival. 
Table 2. Receptors for several growth factors secreted by brain endothelial cells and pericytes are highly expressed by purified CSMNs

\begin{tabular}{|c|c|c|c|c|c|c|c|}
\hline Gene & Probe set & Whole cortex (P3) & CSMNs (P3) & CSMNs (P7) & Ligand & Probe set & VC \\
\hline$i g f 2 r$ & 1367636_at & 446 & 387 & 337 & IGF2 & 1448152_at & 7156 \\
\hline cxcr4 & 1389244_x_at & 2173 & 3286 & 2815 & CXCL12 & 1417574_at & 7874 \\
\hline ptprz1 & 1368350_at & 5506 & 3093 & 2705 & PTN & 1448254_at & 9003 \\
\hline $\operatorname{tgf} \beta r 1$ & 1376636_at & 3406 & 4165 & 2435 & TGF $\beta 2$ & 1450923_at & 2350 \\
\hline itgb1 & 1368819_at & 2079 & 2505 & 2209 & Sema7a & 1459903_at & 6140 \\
\hline ntrk2 & 1368972_at & 3371 & 1896 & 1688 & BDNF & 1422169_a_at & 20 \\
\hline igftr & 1368123_at & 576 & 211 & 196 & IGF1 & 1419519_at & 88 \\
\hline
\end{tabular}

Expression levels are shown in arbitrary units derived from Affymetrix GeneChip operating software. VC, Expression level of indicated ligand in acutely purified postnatal vascular cells (Daneman, Zhou, and Barres, unpublished data).

\section{Brain vascular cells support CSMN health}

In analyzing the genomic expression profile of purified CSMNs, we discovered that they expressed several growth factor receptors that corresponded to ligands produced by brain vascular cells. After further investigation, we observed that medium conditioned by cultures of pure brain vascular endothelial cells could significantly enhance the survival of CSMNs in culture. In addition, the ECM greatly enhanced the morphological health of the CSMNs, with CSMNs cultured in the presence of ECM extending highly elongated and branched neurites. Significantly, this viability-promoting activity in ECM does not derive from BDNF or IGF1, neither of which was expressed by the brain vascular cells. Instead, we found that, among other factors, IGF2, CXCL12, and PTN were expressed by the brain vascular cells. IGF2 is a known neurotrophic factor (Doré et al., 1996; D'Costa et al., 1998; Motoike and Unsicker, 1999; Pu et al., 1999), and its receptor can signal via a G-protein pathway (Hawkes and Kar, 2004; Hawkes et al., 2006). Yet IGF2 has not been considered before in the context of enhancing CSMN viability, although the closely related factor IGF1 is thought to promote CSMN survival. CXCL12 has been implicated in supporting embryonic neuronal survival and migration, and directing the projection of developing axons (including motor neuron axons), but a role in supporting CSMN survival has not been reported (Chalasani et al., 2003; Stumm and Hollt, 2007; Liapi et al., 2008; López-Bendito et al., 2008). PTN is also a known neurotrophic factor, including for SMNs (Mourlevat et al., 2005; Mi et al., 2007), but it also has not been investigated for its effect on CSMNs. We examined the roles of all three of these EC-produced factors in supporting CSMN survival and found that all could similarly promote CSMN viability and neurite extension and that they were as effective as the previously characterized CSMN survival factors BDNF and IGF1. We also found that all three factors together with BDNF could equal the effectiveness of ECM, and that the combined factors in combination with ECM did not further enhance the ability of ECM to support CSMN health. Together, these data indicate that IGF2, CXCL12, and PTN represent novel, ECM-derived survival factors for CSMNs. We also observed that the expression of these survival factors (as well as the expression of TGF $\beta 2$ and Sema7A, the receptors for which are also expressed by CSMNs) was enriched or specific to the brain vasculature relative to other, nonneural tissues. These data indicate that, in addition to forming the blood-brain barrier, another role specific to the CNS endothelial cells and pericytes may be to supply trophic support to CNS neurons.

Vasculature is ubiquitous throughout the brain and present along the CST (Stanfield, 1992), but a role for cerebral vasculature in providing neurotrophic support has not been considered previously. Yet there have been some previous observations indicating that this might be the case. Endothelial cells have been found to promote neural stem cell self-renewal and neuronal production in vitro (Shen et al., 2004). In addition to a hypothesized role in controlling cell fate decisions, our data indicate that endothelial cells may also support the survival of neurons newly generated from neural stem cells. In addition, mixed ECs cultured by Leventhal et al. (1999) could support neurogenesis from neural precursors and, via the production of BDNF, some neuronal survival. However, these vascular cells were obtained from human umbilical cord, and therefore are distinct from the CNSderived vascular cells we have used here. Although we have shown that our cultures of pure brain ECs do not produce BDNF, they instead produce several additional factors that support the survival and morphological maturation of isolated CNS CSMNs. Furthermore, analysis of both our gene chip expression data and Allen Brain Atlas in situs indicates that receptors for ECexpressed trophic factors are not restricted to layer $\mathrm{V}$ and are instead expressed more broadly throughout the CNS. Vascular endothelial growth factor (VEGF) and erythropoietin (EPO) are factors primarily associated with supporting the survival of vascular and hematopoietic cells, yet recent reports have also indicated potential neurotrophic roles for these factors both in vitro and in mouse models of ALS (Zachary, 2005; Koh et al., 2007; Wang et al., 2007; van der Kooij et al., 2008). Given the low levels of VEGF and EPO receptors on neurons (Cahoy et al., 2008), it is possible that the in vivo neuroprotective effects reported for VEGF and EPO may derive primarily from promotion of vascular cell growth and, therefore, total production of vascular-derived neuronal survival factors such as IGF2, CXCL12, and PTN.

Understanding the molecular factors that control the survival of CSMNs contributes to our understanding of the development, plasticity, and function of the brain. In addition, our findings may lead to a better understanding of the vulnerabilities of CSMNs as observed in a variety of neurodevelopmental and neurodegenerative disorders, e.g., ALS and spinal cord injuries. Finally, our data indicate that the vascular cells of the brain should be considered as a previously overlooked potential source of trophic support for several populations of CNS neurons.

\section{References}

Aghajanian GK, Rasmussen K (1989) Intracellular studies in the facial nucleus illustrating a simple new method for obtaining viable motoneurons in adult rat brain slices. Synapse 3:331-338.

Arlotta P, Molyneaux BJ, Chen J, Inoue J, Kominami R, Macklis JD (2005) Neuronal subtype-specific genes that control corticospinal motor neuron development in vivo. Neuron 45:207-221.

Bareyre FM, Kerschensteiner M, Misgeld T, Sanes JR (2005) Transgenic labeling of the corticospinal tract for monitoring axonal responses to spinal cord injury. Nat Med 11:1355-1360.

Barres BA, Silverstein BE, Corey DP, Chun LL (1988) Immunological, morphological, and electrophysiological variation among retinal ganglion cells purified by panning. Neuron 1:791-803.

Bonfanti L, Strettoi E, Chierzi S, Cenni MC, Liu XH, Martinou JC, Maffei L, RabacchiSA (1996) Protection of retinal ganglion cells from natural and 
axotomy-induced cell death in neonatal transgenic mice overexpressing bcl-2. J Neurosci 16:4186-4194.

Brewer GJ, Torricelli JR, Evege EK, Price PJ (1993) Optimized survival of hippocampal neurons in B27-supplemented Neurobasal, a new serumfree medium combination. J Neurosci Res 35:567-576.

Cahoy JD, Emery B, Kaushal A, Foo LC, Zamanian JL, Christopherson KS, Xing Y, Lubischer JL, Krieg PA, Krupenko SA, Thompson WJ, Barres BA (2008) A transcriptome database for astrocytes, neurons, and oligodendrocytes: a new resource for understanding brain development and function. J Neurosci 28:264-278.

Catapano LA, Arnold MW, Perez FA, Macklis JD (2001) Specific neurotrophic factors support the survival of cortical projection neurons at distinct stages of development. J Neurosci 21:8863-8872.

Chalasani SH, Baribaud F, Coughlan CM, Sunshine MJ, Lee VM, Doms RW, Littman DR, Raper JA (2003) The chemokine stromal cell-derived factor-1 promotes the survival of embryonic retinal ganglion cells. J Neurosci 23:4601-4612.

Chinnapen DJ, Chinnapen H, Saslowsky D, Lencer WI (2007) Rafting with cholera toxin: endocytosis and trafficking from plasma membrane to ER. FEMS Microbiol Lett 266:129-137.

Christopherson KS, Ullian EM, Stokes CC, Mullowney CE, Hell JW, Agah A, Lawler J, Mosher DF, Bornstein P, Barres BA (2005) Thrombospondins are astrocyte-secreted proteins that promote CNS synaptogenesis. Cell 120:421-433.

Cuatrecasas P (1973) Gangliosides and membrane receptors for cholera toxin. Biochemistry 12:3558-3566.

D'Costa AP, Prevette DM, Houenou LJ, Wang S, Zackenfels K, Rohrer H, Zapf J, Caroni P, Oppenheim RW (1998) Mechanisms of insulin-like growth factor regulation of programmed cell death of developing avian motoneurons. J Neurobiol 36:379-394.

Doherty P, Walsh FS (1987) Ganglioside GM1 antibodies and B-cholera toxin bind specifically to embryonic chick dorsal root ganglion neurons but do not modulate neurite regeneration. J Neurochem 48:1237-1244.

Doré S, Krieger C, Kar S, Quirion R (1996) Distribution and levels of insulin-like growth factor (IGF-I and IGF-II) and insulin receptor binding sites in the spinal cords of amyotrophic lateral sclerosis (ALS) patients. Brain Res Mol Brain Res 41:128-133.

Giehl KM, Schütte A, Mestres P, Yan Q (1998) The survival-promoting effect of glial cell line-derived neurotrophic factor on axotomized corticospinal neurons in vivo is mediated by an endogenous brain-derived neurotrophic factor mechanism. J Neurosci 18:7351-7360.

Giehl KM, Röhrig S, Bonatz H, Gutjahr M, Leiner B, Bartke I, Yan Q, Reichardt LF, Backus C, Welcher AA, Dethleffsen K, Mestres P, Meyer M (2001) Endogenous brain-derived neurotrophic factor and neurotrophin-3 antagonistically regulate survival of axotomized corticospinal neurons in vivo. J Neurosci 21:3492-3502.

Gorgels TG (1990) A quantitative analysis of axon outgrowth, axon loss, and myelination in the rat pyramidal tract. Brain Res Dev Brain Res 54:51-61.

Hammond EN, Tetzlaff W, Mestres P, Giehl KM (1999) BDNF, but not NT-3, promotes long-term survival of axotomized adult rat corticospinal neurons in vivo. Neuroreport 10:2671-2675.

Hanson MG Jr, Shen S, Wiemelt AP, McMorris FA, Barres BA (1998) Cyclic AMP elevation is sufficient to promote the survival of spinal motor neurons in vitro. J Neurosci 18:7361-7371.

Hawkes C, Kar S (2004) The insulin-like growth factor-II/mannose-6phosphate receptor: structure, distribution and function in the central nervous system. Brain Res Brain Res Rev 44:117-140.

Hawkes C, Jhamandas JH, Harris KH, Fu W, MacDonald RG, Kar S (2006) Single transmembrane domain insulin-like growth factor-II/mannose-6phosphate receptor regulates central cholinergic function by activating a G-protein-sensitive, protein kinase C-dependent pathway. J Neurosci 26:585-596.

Herculano-Houzel S, Lent R (2005) Isotropic fractionator: a simple, rapid method for the quantification of total cell and neuron numbers in the brain. J Neurosci 25:2518-2521.

Herculano-Houzel S, Mota B, Lent R (2006) Cellular scaling rules for rodent brains. Proc Natl Acad Sci U S A 103:12138-12143.

Junger H, Junger WG (1998) CNTF and GDNF, but not NT-4, support corticospinal motor neuron growth via direct mechanisms. Neuroreport 9:3749-3754.

Katz LC, Burkhalter A, Dreyer WJ (1984) Fluorescent latex microspheres as a retrograde neuronal marker for in vivo and in vitro studies of visual cortex. Nature 310:498-500.

Kaur C, Ling EA (1991) Study of the transformation of amoeboid microglial cells into microglia labelled with the isolectin Griffonia simplicifolia in postnatal rats. Acta Anat (Basel) 142:118-125.

Kaur C, Ling EA, Wong WC (1990) Lectin labelling of amoeboid microglial cells in the brain of postnatal rats. J Anat 173:151-160.

Koh SH, Kim Y, Kim HY, Cho GW, Kim KS, Kim SH (2007) Recombinant human erythropoietin suppresses symptom onset and progression of G93A-SOD1 mouse model of ALS by preventing motor neuron death and inflammation. Eur J Neurosci 25:1923-1930.

Leventhal C, Rafii S, Rafii D, Shahar A, Goldman SA (1999) Endothelial trophic support of neuronal production and recruitment from the adult mammalian subependyma. Mol Cell Neurosci 13:450-464.

Liapi A, Pritchett J, Jones O, Fujii N, Parnavelas JG, Nadarajah B (2008) Stromal-derived factor 1 signalling regulates radial and tangential migration in the developing cerebral cortex. Dev Neurosci 30:117-131.

López-Bendito G, Sánchez-Alcañiz JA, Pla R, Borrell V, Picó E, Valdeolmillos M, Marín O (2008) Chemokine signaling controls intracortical migration and final distribution of GABAergic interneurons. J Neurosci 28:1613-1624.

Lu P, Blesch A, Tuszynski MH (2001) Neurotrophism without neurotropism: BDNF promotes survival but not growth of lesioned corticospinal neurons. J Comp Neurol 436:456-470.

Masco D, Van de Walle M, Spiegel S (1991) Interaction of ganglioside GM1 with the $\mathrm{B}$ subunit of cholera toxin modulates growth and differentiation of neuroblastoma N18 cells. J Neurosci 11:2443-2452.

Meyer-Franke A, Kaplan MR, Pfrieger FW, Barres BA (1995) Characterization of the signaling interactions that promote the survival and growth of developing retinal ganglion cells in culture. Neuron 15:805-819.

Meyer-Franke A, Wilkinson GA, Kruttgen A, Hu M, Munro E, Hanson MG Jr, Reichardt LF, Barres BA (1998) Depolarization and cAMP elevation rapidly recruit TrkB to the plasma membrane of CNS neurons. Neuron 21:681-693.

Mi H, Haeberle H, Barres BA (2001) Induction of astrocyte differentiation by endothelial cells. J Neurosci 21:1538-1547.

Mi R, Chen W, Höke A (2007) Pleiotrophin is a neurotrophic factor for spinal motor neurons. Proc Natl Acad Sci U S A 104:4664-4669.

Molyneaux BJ, Arlotta P, Menezes JR, Macklis JD (2007) Neuronal subtype specification in the cerebral cortex. Nat Rev 8:427-437.

Motoike T, Unsicker K (1999) Identification of a potent neurotrophic substance for ciliary ganglionic neurons in fetal calf serum as insulin-like growth factor II. J Neurosci Res 56:386-396.

Mourlevat S, Debeir T, Ferrario JE, Delbe J, Caruelle D, Lejeune O, Depienne C, Courty J, Raisman-Vozari R, Ruberg M (2005) Pleiotrophin mediates the neurotrophic effect of cyclic AMP on dopaminergic neurons: analysis of suppression-subtracted cDNA libraries and confirmation in vitro. Exp Neurol 194:243-254.

Mutoh T, Tokuda A, Guroff G, Fujiki N (1993) The effect of the B subunit of cholera toxin on the action of nerve growth factor on PC12 cells. J Neurochem 60:1540-1547.

Nedelkoska L, Benjamins JA (1998) Binding of cholera toxin B subunit: a surface marker for murine microglia but not oligodendrocytes or astrocytes. J Neurosci Res 53:605-612.

Nickel W (2005) Unconventional secretory routes: direct protein export across the plasma membrane of mammalian cells. Traffic 6:607-614.

Oudega M, Varon S, Hagg T (1994) Distribution of corticospinal motor neurons in the postnatal rat: quantitative evidence for massive collateral elimination and modest cell death. J Comp Neurol 347:115-126.

Ozdinler PH, Macklis JD (2006) IGF-I specifically enhances axon outgrowth of corticospinal motor neurons. Nat Neurosci 9:1371-1381.

Pasinelli P, Brown RH (2006) Molecular biology of amyotrophic lateral sclerosis: insights from genetics. Nat Rev 7:710-723.

Pelkmans L, Zerial M (2005) Kinase-regulated quantal assemblies and kissand-run recycling of caveolae. Nature 436:128-133.

Potts RA, Dreher B, Bennett MR (1982) The loss of ganglion cells in the developing retina of the rat. Brain Res 255:481-486.

Pu SF, Zhuang HX, Marsh DJ, Ishii DN (1999) Insulin-like growth factor-II increases and IGF is required for postnatal rat spinal motoneuron survival following sciatic nerve axotomy. J Neurosci Res 55:9-16.

Reichert F, Rotshenker S (1996) Deficient activation of microglia during optic nerve degeneration. J Neuroimmunol 70:153-161. 
Riddle DR, Lo DC, Katz LC (1995) NT-4-mediated rescue of lateral geniculate neurons from effects of monocular deprivation. Nature 378:189-191.

Riddle DR, Katz LC, Lo DC (1997) Focal delivery of neurotrophins into the central nervous system using fluorescent latex microspheres. Biotechniques 23:928-934, 936-937.

Schumacher R, Soos MA, Schlessinger J, Brandenburg D, Siddle K, Ullrich A (1993) Signaling-competent receptor chimeras allow mapping of major insulin receptor binding domain determinants. J Biol Chem 268:1087-1094.

Schütte A, Yan Q, Mestres P, Giehl KM (2000) The endogenous survival promotion of axotomized rat corticospinal neurons by brain-derived neurotrophic factor is mediated via paracrine, rather than autocrine mechanisms. Neurosci Lett 290:185-188.

Schwab ME (2002) Repairing the injured spinal cord. Science 295:1029-1031.

Shen Q, Goderie SK, Jin L, Karanth N, Sun Y, Abramova N, Vincent P, Pumiglia K, Temple S (2004) Endothelial cells stimulate self-renewal and expand neurogenesis of neural stem cells. Science 304:1338-1340.

Spangler BD (1992) Structure and function of cholera toxin and the related Escherichia coli heat-labile enterotoxin. Microbiol Rev 56:622-647.

Spreafico R, Frassoni C, Arcelli P, Selvaggio M, De Biasi S (1995) In situ labeling of apoptotic cell death in the cerebral cortex and thalamus of rats during development. J Comp Neurol 363:281-295.

Stanfield BB (1992) The development of the corticospinal projection. Prog Neurobiol 38:169-202.

Streit WJ, Kreutzberg GW (1987) Lectin binding by resting and reactive microglia. J Neurocytol 16:249-260.
Stumm R, Hollt V (2007) CXC chemokine receptor 4 regulates neuronal migration and axonal pathfinding in the developing nervous system: implications for neuronal regeneration in the adult brain. J Mol Endocrinol 38:377-382.

Terashima T (1995) Anatomy, development and lesion-induced plasticity of rodent corticospinal tract. Neurosci Res 22:139-161.

Tuszynski MH, Grill R, Jones LL, Brant A, Blesch A, Löw K, Lacroix S, Lu P (2003) NT-3 gene delivery elicits growth of chronically injured corticospinal axons and modestly improves functional deficits after chronic scar resection. Exp Neurol 181:47-56.

Ullian EM, Sapperstein SK, Christopherson KS, Barres BA (2001) Control of synapse number by glia. Science 291:657-661.

van der Kooij MA, Groenendaal F, Kavelaars A, Heijnen CJ, van Bel F (2008) Neuroprotective properties and mechanisms of erythropoietin in in vitro and in vivo experimental models for hypoxia/ischemia. Brain Res Rev, in press.

Wang Y, Mao XO, Xie L, Banwait S, Marti HH, Greenberg DA, Jin K (2007) Vascular endothelial growth factor overexpression delays neurodegeneration and prolongs survival in amyotrophic lateral sclerosis mice. J Neurosci 27:304-307.

Wu G, Nakamura K, Ledeen RW (1994) Inhibition of neurite outgrowth of neuroblastoma Neuro-2a cells by cholera toxin B-subunit and anti-GM1 antibody. Mol Chem Neuropathol 21:259-271.

Young RW (1984) Cell death during differentiation of the retina in the mouse. J Comp Neurol 229:362-373.

Zachary I (2005) Neuroprotective role of vascular endothelial growth factor: signalling mechanisms, biological function, and therapeutic potential. Neurosignals 14:207-221. 